\title{
Microstructure and Carburization Detection in HP Alloy Pyrolysis Tubes
}

\author{
A. C. McLeod $^{1}$ - C. M. Bishop ${ }^{1}$ K. J. Stevens ${ }^{2} \cdot$ M. V. Kral ${ }^{1}$
}

Received: 22 March 2015/Revised: 4 June 2015/Accepted: 7 June 2015/Published online: 25 June 2015

(C) Springer Science+Business Media New York and ASM International 2015

\begin{abstract}
A highly carburized HP40-Mod alloy ethylene pyrolysis tube was characterized by means of scanning electron microscopy with backscatter electron imaging, electron back-scattered diffraction, energy dispersive spectroscopy, and etching using the NACE International Standard Test Method for evaluation of carburization of ethylene pyrolysis tubes. The response of the tube to eddy current non-destructive testing was measured using the carburization crawler under development at Quest Integrity NZL Ltd. The matrix was significantly depleted of chromium, as low as $4 \mathrm{wt} \% \mathrm{Cr}$ at the inner wall. $\mathrm{M}_{23} \mathrm{C}_{6}$ carbides transformed to $\mathrm{M}_{7} \mathrm{C}_{3}$ at the inner wall region and $\mathrm{NbC}$ carbides partially transformed to the chromium-rich $\eta$-carbide at the outer wall region, both of which likely contributed to the chromium depletion of the matrix. The present results indicate that the NACE etchant attacks the austenitic matrix where chromium content is below approximately $12 \mathrm{wt} \%$. A comparison to other ex-service tubes indicates that matrix chromium content and the location of the $\mathrm{M}_{23} \mathrm{C}_{6} / \mathrm{M}_{7} \mathrm{C}_{3}$ transformation front are useful microstructural characteristics for interpreting eddy current NDT response.
\end{abstract}

M. V. Kral

milo.kral@canterbury.ac.nz

1 Department of Mechanical Engineering, University of Canterbury, Private Bag 4800, Christchurch 8140, New Zealand

2 Quest Integrity NZL Ltd, Part of the Quest Integrity Group, Gracefield Research Centre, 69 Gracefield Road, PO Box 38-096, Lower Hutt 5045, New Zealand
Keywords Scanning Electron Microscopy · Steels · Phase transformations - Metallography

\section{Introduction}

Ethylene is used extensively in the production of plastics, cabling, and automotive products, and is typically produced by the thermal cracking (pyrolysis) of more complex hydrocarbons, such as naphtha or ethane, at $700-1100{ }^{\circ} \mathrm{C}$ inside a tube in a pyrolysis furnace. In order to provide the corrosion resistance and creep strength necessary to withstand such harsh operating conditions, the heat resisting (H-series) centrifugally cast, austenitic stainless steels are typically used for pyrolysis tubes [1,2].

Carburization is one of the major degradation mechanisms of pyrolysis tubes [3]. High carbon potentials at the inner diameter due to the cracking reaction and high tube temperatures result in the diffusion of carbon into the tubes, where it combines with chromium and other carbideforming elements to grow existing carbides and create new ones $[4,5]$. The carbides undergo chemical and morphological changes, initially coarsening and coalescing, followed by phase transformation [4].

Internal carbide precipitation results in considerable volume increases, changes in thermal expansion coefficient of the carburized zone, and embrittlement. The result is a reduction in ductility as well as increase in internal stresses, adversely affecting the creep properties and the ability of the tube to withstand thermal cycling [2, 5-8].

Consequently, there is interest in non-destructive testing (NDT) methods to evaluate the level of carburization of tubes in situ. Carbide precipitation and the segregation of elements in HP alloy tubes result in a change in the magnetic properties of the carburized region, allowing 
carburization to be detected non-destructively using eddy current techniques $[6,7,9]$. However, the eddy current systems require calibration using ex-service pyrolysis tubes that have had their microstructure, mechanical properties, and magnetic response characterized [6,9].

This paper presents the results of detailed microstructural characterization of a highly carburized ex-service ethylene pyrolysis tube. The purpose of the paper is to determine whether there are certain microstructural features or compositional variations (e.g., chromium depletion) that dictate the eddy current NDT response of ex-service tubes.

\section{Materials and Methods}

An ex-service HP40-Mod alloy ethylene pyrolysis tube was examined. It had spent approximately 4 years in service, at 20 psig and $1300{ }^{\circ} \mathrm{F}\left(138 \mathrm{kPag}\right.$ and $\left.704^{\circ} \mathrm{C}\right)$. The typical as-cast composition of an HP40-Mod alloy is given in Table 1 [10]. The tube had an outer diameter of $100 \mathrm{~mm}$, and an average wall thickness of $7.7 \mathrm{~mm}$.

A ring approximately $10-\mathrm{mm}$ thick was cut from the tube, and a metallographic sample approximately $8 \times 10 \mathrm{~mm}$ was sectioned and mounted in order to observe the through-wall face. The sample was ground on $\mathrm{SiC}$ paper at 180, 240, 320, 400, and 600 grit, then polished with 9 and $3 \mu \mathrm{m}$ diamond suspension. A final polish to a $0.02-\mu \mathrm{m}$ finish was achieved using colloidal silica. Prior to electron back-scattered diffraction (EBSD) analysis, the sample was etched in glyceregia for $10 \mathrm{~s}$, in order to increase the visibility of the precipitates. The composition of the glyceregia was $30 \mathrm{ml}$ of glycerol, $30 \mathrm{ml}$ of hydrochloric acid, and $10 \mathrm{ml}$ of nitric acid.

Phase identification was carried out using a JEOL JSM 7000 field emission scanning electron microscope (FESEM), equipped with a JEOL JED-2300 energy dispersive X-ray spectroscopy (EDS) system, and a JEOL 6100 SEM, equipped with an Oxford HKL Channel 5 EBSD system. A combination of back scatter electron (BSE) imaging, EDS, and EBSD was used to identify the precipitate phases present in the tubes and determine their locations across the tube wall. BSE images were taken at set intervals across the tube wall, with multiple EDS spectra taken for each phase at each location. The appearance of each phase in the BSE images and the composition determined by EDS were used to produce a list of candidates for each phase. Crystal structure was then confirmed using EBSD.

The chromium depletion of the matrix was measured using EDS. The spectra were taken at a distance of

Table 1 Typical Composition of an HP40-Mod alloy [10]

\begin{tabular}{llllllll}
\hline Wt\% & $\mathrm{C}$ & $\mathrm{Cr}$ & $\mathrm{Ni}$ & $\mathrm{Nb}$ & $\mathrm{Si}$ & $\mathrm{Mn}$ & $\mathrm{Fe}$ \\
\hline HP-40-Mod & 0.4 & 25 & 35 & 1.5 & 1.5 & 1.5 & Bal. \\
\hline
\end{tabular}

approximately $10 \mu \mathrm{m}$ from primary chromium carbides. In the highly carburized region of the sample, $10 \mu \mathrm{m}$ was approximately the distance at which a point in the matrix was equidistant from surrounding chromium carbides.

Progressive deep etching was used in order to gain an understanding of the three-dimensional structure of the carbide network. The sample was imaged in BSE mode at multiple locations in the as-polished condition, and the same locations were imaged in SEI mode after 15, 30, 60, 120 , and 180 min etching using glyceregia. Glyceregia was chosen as the etchant as in HP alloys it only etches away austenite, leaving the carbide network intact [10].

The etching method described in the NACE International Standard Test Method for evaluation of carburization of ethylene pyrolysis tubes [11] was used to semi-quantitatively measure the extent of carburization in the ex-service tube. The etchant was composed of $200 \mathrm{ml}$ of nitric acid, $70 \mathrm{ml}$ of hydrofluoric acid, and $670 \mathrm{ml}$ of distilled water. The etching sample was taken from the sectioned ring, adjacent to the metallographic sample. Upon completion of the etching, the sample was observed under an Olympus SZH10 stereo-optical microscope.

Precipitate-matrix orientation relationships were analyzed using EBSD. EBSD patterns (EBSPs) were obtained from the precipitates and the austenitic matrix directly adjacent to each precipitate. The Euler angles $\left(\varphi_{1}, \varphi_{2}, \Phi\right)$ that describe the crystallographic orientation with respect to a reference axis system were calculated from the indexed EBSPs. The Euler angles were used to calculate an orientation matrix for each point of analysis, and then the misorientation between the two points was calculated. The disorientation (i.e., the variant with the smallest rotation angle $\theta$ about the rotation axis $[u v w]$ ) was then calculated by considering symmetry operations, e.g., the 24 crystallographic equivalents for the cubic system [12].

The eddy current NDT response of the ex-service tube was measured using the eddy current NDT carburization crawler that is being developed by Quest Integrity NZL Ltd. The system uses cylindrical coils to probe the tube with variable frequency electromagnetic waves, and measures the changes in coil properties (i.e., inductance, resistance), which differ depending on the level of carburization of the tube.

\section{Results and Discussion}

\section{Macrostructure}

Figure 1 shows the through-wall grain structure of the tube. Centrifugally cast HP alloy tubes display either a completely columnar structure or a mixed columnar-equiaxed structure, depending on the centrifugal casting conditions 


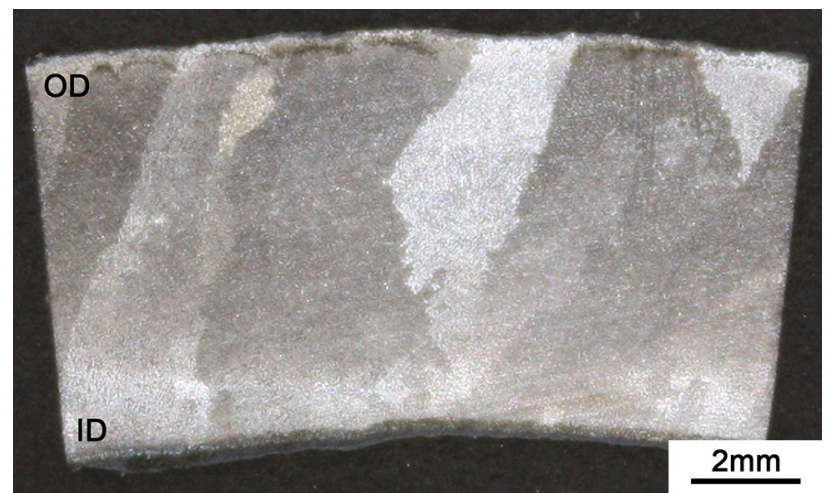

Fig. 1 Low-magnification image showing the through-wall grain structure of the ex-service tube (etchant: Marbles reagent)

(for example, the pouring temperature and the cooling rate) [13-15]. The $100 \%$ columnar structure of the ex-service tube indicates a high cooling rate induced during casting.

\section{Phase Identification}

A number of different phases were present across the wall thickness of the ex-service tube, including carbides, carbonitrides, and silicon-rich phases. A schematic of the tube wall summarizing the locations of interest and the phases identified is shown in Fig. 2.

\section{Chromium Carbides}

The microstructure across the tube wall consisted of an austenitic matrix with a network of coarse chromium-rich carbides and niobium-rich carbides. The chromium-rich carbides in the $0.4-5 \mathrm{~mm}$ region of the tube wall were identified as $\mathrm{M}_{7} \mathrm{C}_{3}$ (where $\mathrm{M}=\mathrm{Fe}, \mathrm{Cr}, \mathrm{Ni}$ ), and those in the 5-7.2 mm region were identified as $\mathrm{M}_{23} \mathrm{C}_{6}$. The niobium-rich carbides were identified as $\mathrm{NbC}$.

The progression of the microstructure in the $0.4-5 \mathrm{~mm}$ region of the tube wall is shown in Fig. 3. The ratio of $\mathrm{Cr}$ to $\mathrm{Fe}$ in the $\mathrm{M}_{7} \mathrm{C}_{3}$ carbides increased as the distance into the tube wall from the inner diameter increased, as shown in Fig. 4. The Ni content remained constant at $1-2$ at.\%.

$\mathrm{M}_{7} \mathrm{C}_{3}$ is formed by the conversion of $\mathrm{M}_{23} \mathrm{C}_{6}$, as a result of the increasing $\mathrm{C} / \mathrm{Cr}$ ratio at the inner wall region due to carbon diffusion from the inner diameter [5]. The composition of the $\mathrm{M}_{7} \mathrm{C}_{3}$ depends on the local carbon activity [16, 17], and thus, in the ex-service tube, on the distance from the inner diameter. The main metal component of $\mathrm{M}_{7} \mathrm{C}_{3}$ is $\mathrm{Cr}$, but with increasing carbon activity an increased amount of iron is substituted for chromium [17-19].

The $\mathrm{M}_{7} \mathrm{C}_{3} / \mathrm{M}_{23} \mathrm{C}_{6}$ transformation front was located at a distance of approximately $5 \mathrm{~mm}$ from the inner diameter of the tube. The $\mathrm{M}_{23} \mathrm{C}_{6}$ carbide had a medium gray contrast in the BSE images, as shown in Fig. 5. The transition between

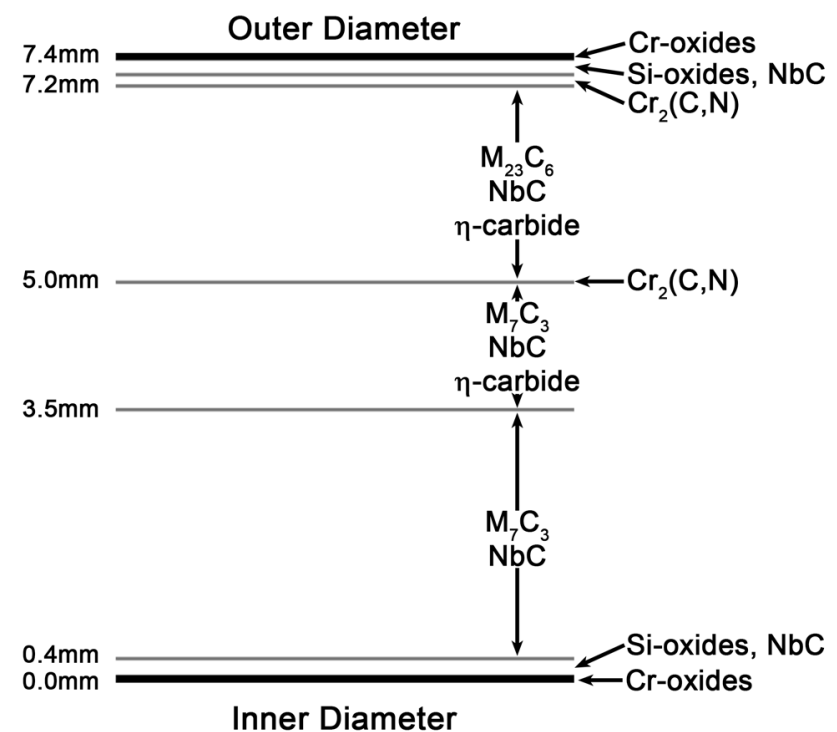

Fig. 2 Schematic of the tube wall summarizing the locations of the phases identified

$\mathrm{M}_{7} \mathrm{C}_{3}$ and $\mathrm{M}_{23} \mathrm{C}_{6}$ occurred over a very narrow range, with a band of approximately $200 \mu \mathrm{m}$ in width where both $\mathrm{M}_{7} \mathrm{C}_{3}$ and $\mathrm{M}_{23} \mathrm{C}_{6}$ were present.

The appearance of the $\mathrm{M}_{7} \mathrm{C}_{3}$ carbides changed across the wall, with a separate phase appearing to be encapsulated, or contained, within the $\mathrm{M}_{7} \mathrm{C}_{3}$, giving a "porous" appearance in two dimensions. The contained phase was present in the carbides across the $0.4-5 \mathrm{~mm}$ wall region, but appeared to become more prevalent as distance from the inner diameter increased, as evidenced in Fig. 3. The $\mathrm{M}_{7} \mathrm{C}_{3}$ carbides at a distance of $5 \mathrm{~mm}$ into the tube wall appear significantly more "porous" than those closer to the inner diameter. EDS and EBSD analysis identified the contained phase as austenite.

The "porous" appearance of the $\mathrm{M}_{7} \mathrm{C}_{3}$ carbides, without identifying the phase present inside the carbides, was previously reported by Christ [17] to occur during carburization of a 304L type stainless steel, and by Waldenström [20] in a $\mathrm{Fe}-\mathrm{Cr}-\mathrm{Ni}-\mathrm{Mn}-\mathrm{C}$ alloy. Kaya [4] also observed this phenomenon in an ex-service HK40 alloy ethylene pyrolysis tube, identifying the phase present inside the $\mathrm{M}_{7} \mathrm{C}_{3}$ carbides as austenite. All three studies attribute the "porous" appearance of the $\mathrm{M}_{7} \mathrm{C}_{3}$ carbides to its transformation from $\mathrm{M}_{23} \mathrm{C}_{6}$ by a eutectoid reaction during carburization, with Kaya defining the transformation as $\mathrm{M}_{23} \mathrm{C}_{6} \rightarrow \mathrm{M}_{7} \mathrm{C}_{3}+\gamma$ (where $\gamma=$ austenite).

Kaya proposed that the excess elements (presumably $\mathrm{Fe}$, $\mathrm{Cr}$, and $\mathrm{Ni}$ [18], as $\mathrm{M}_{7} \mathrm{C}_{3}$ has a lower ratio of $\mathrm{M}$ to $\mathrm{C}$ ) that cannot be accommodated in the $\mathrm{M}_{7} \mathrm{C}_{3}$ carbides upon the transformation from $\mathrm{M}_{23} \mathrm{C}_{6}$ would form the austenite phase regions in the $\mathrm{M}_{7} \mathrm{C}_{3}$ carbides, and that these austenite regions may nucleate on the $\mathrm{M}_{23} \mathrm{C}_{6} / \mathrm{M}_{7} \mathrm{C}_{3}$ transformation 


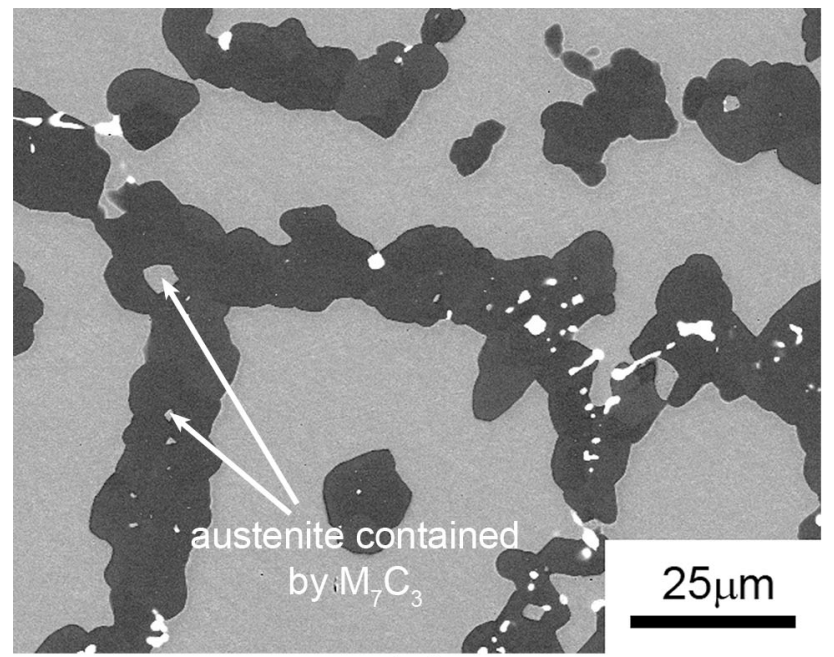

(a)

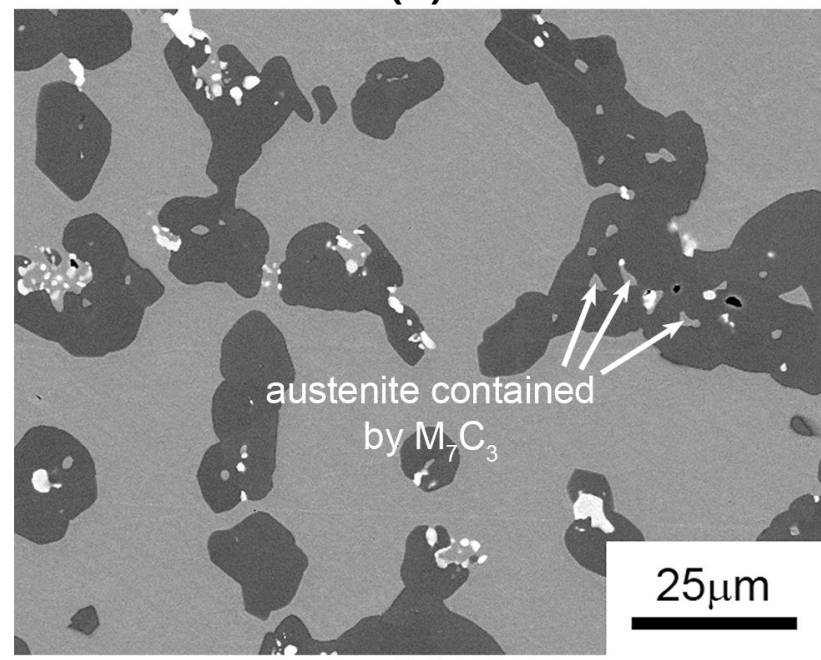

(b)

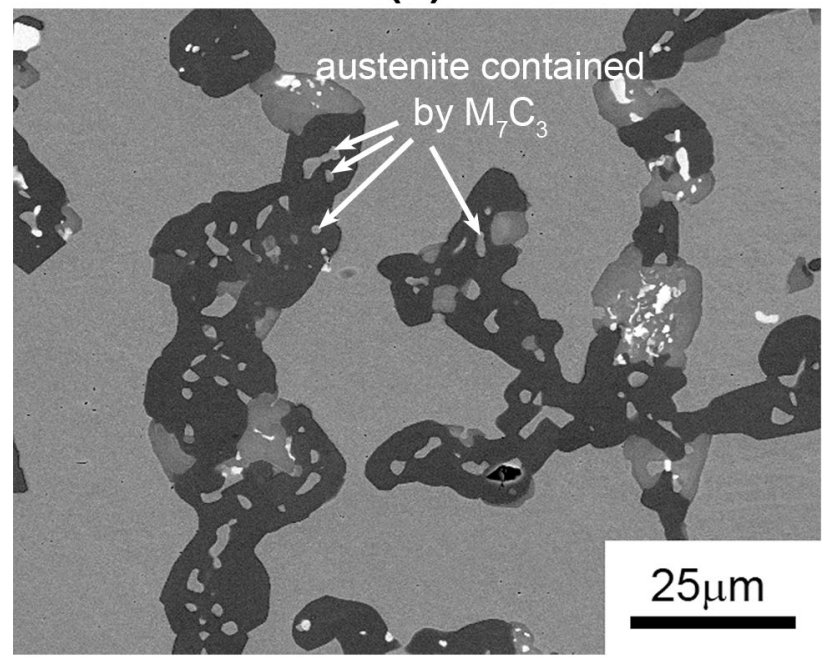

(c)

Fig. 3 BSE micrographs of the microstructure at (a) $1.0 \mathrm{~mm}$, (b) $3.0 \mathrm{~mm}$, and (c) $5.0 \mathrm{~mm}$ from the inner diameter

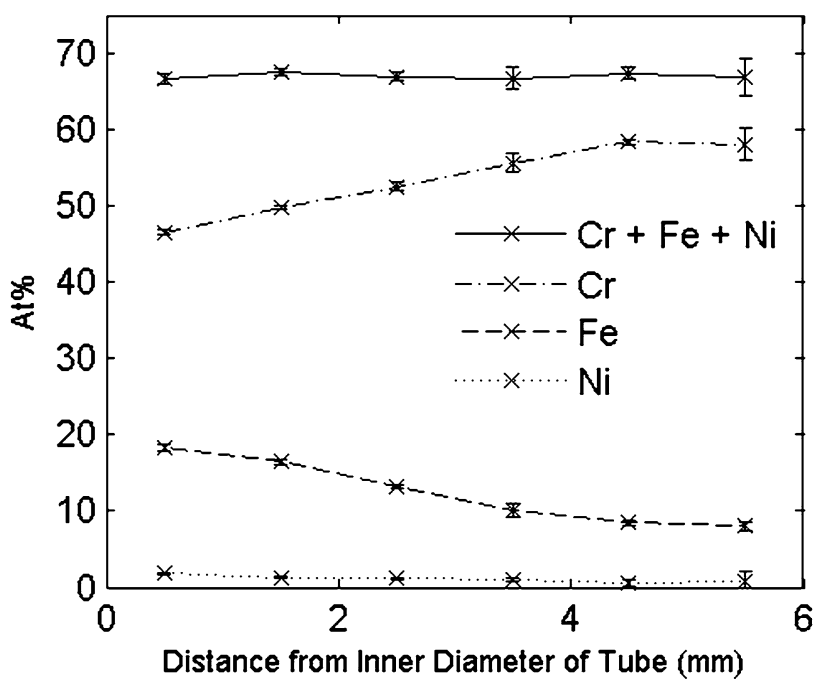

Fig. 4 Change in composition of the $\mathrm{M}_{7} \mathrm{C}_{3}$ carbides with distance from the inner diameter. Results from three EDS spectra were averaged at each location

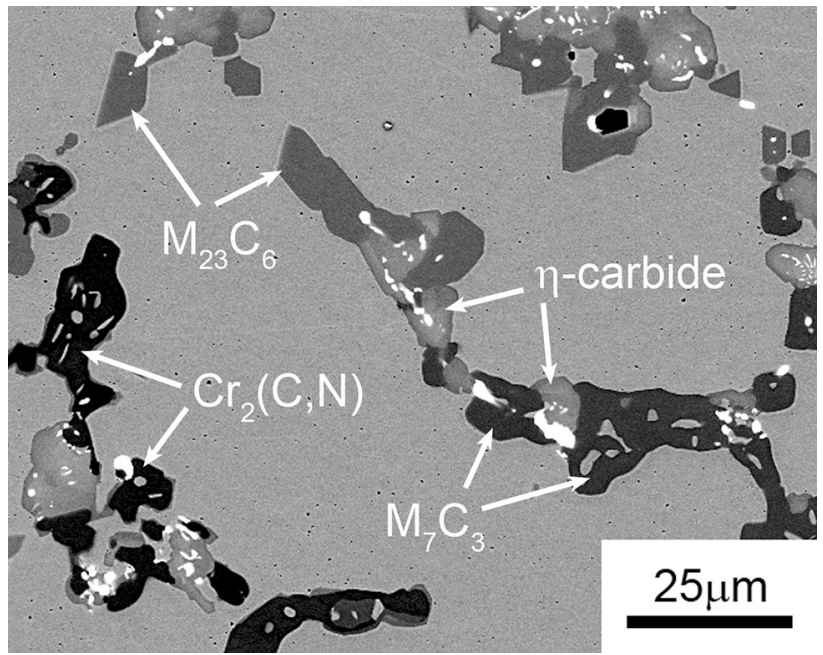

Fig. 5 BSE micrograph indicating the phases present at the $\mathrm{M}_{7} \mathrm{C}_{3} /$ $\mathrm{M}_{23} \mathrm{C}_{6}$ transformation front

front, or alternatively behind the moving front on the defects present in the $\mathrm{M}_{7} \mathrm{C}_{3}$ carbides.

EBSD analysis of 65 contained austenite-matrix pairs enabled the disorientation between the contained austenite regions and the adjacent austenitic matrix to be calculated. Figure 6 shows the relative frequency of the disorientation angle. $69 \%$ of the analyzed contained austenite pairs had a disorientation of less than $10^{\circ}$, typical of a cube-cube orientation with the austenitic matrix. $18 \%$ of the analyzed pairs displayed disorientations close to $60^{\circ}$, and the calculated disorientation axes for these pairs were close to [111]-typical of a twin orientation. The remaining contained austenite displayed no particular orientation 


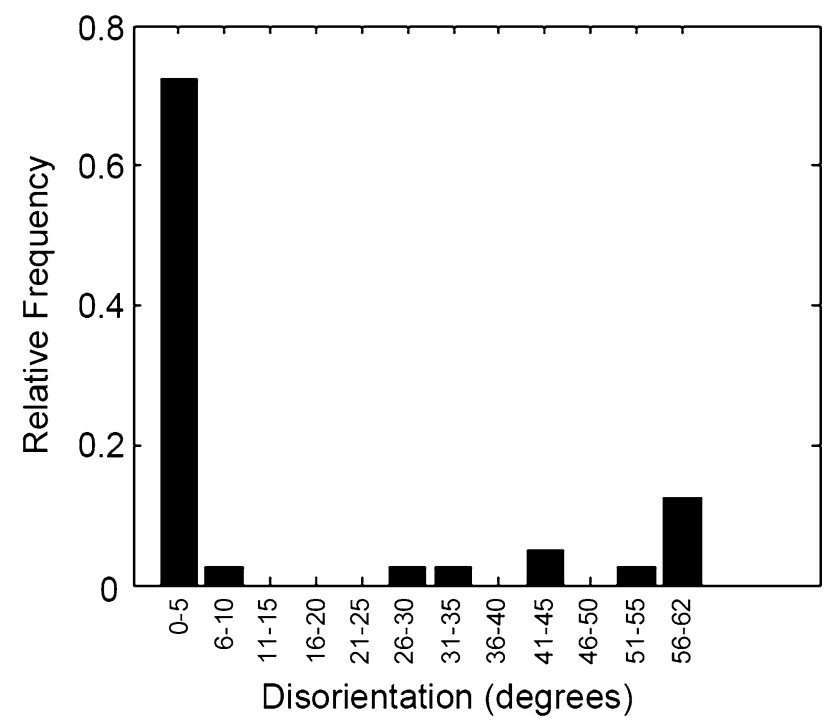

Fig. 6 Relative frequency of angle of disorientation for contained austenite-austenitic matrix pairs

relationship with the austenitic matrix, indicating that no other rational orientations were obtained.

Progressive deep etching (Fig. 7) revealed that areas that appeared as open matrix in the as-polished condition became enclosed by $\mathrm{M}_{7} \mathrm{C}_{3}$ carbides beneath the plane of polish. If the plane of polish was further down into the sample, these regions would have appeared as austenite contained within the $\mathrm{M}_{7} \mathrm{C}_{3}$ carbides. Even though the carbide network may have appeared disconnected in the aspolished condition, the deep etch revealed that the carbides have a high level of connectivity in three dimensions.

Near the inner diameter of the tube, the $\mathrm{M}_{7} \mathrm{C}_{3}$ carbides appeared to be composed of many rounded grains which were very closely packed. Closer to the $\mathrm{M}_{7} \mathrm{C}_{3} / \mathrm{M}_{23} \mathrm{C}_{6}$ transformation front, there were regions where the $\mathrm{M}_{7} \mathrm{C}_{3}$ grains were closely packed, but also regions where the grains were more loosely packed, as shown in Fig. 8. If the plane of polish had been further down in the sample, the gaps in between the grains in the loosely packed regions would have appeared as austenite contained by $\mathrm{M}_{7} \mathrm{C}_{3}$ carbides in two dimensions. In contrast to the $\mathrm{M}_{7} \mathrm{C}_{3}$ carbides, the $\mathrm{M}_{23} \mathrm{C}_{6}$ carbides appeared to be composed of many closely packed angular grains, as shown in Fig. 9.

The space groups and lattice parameters of the $\mathrm{M}_{7} \mathrm{C}_{3}$ and $\mathrm{M}_{23} \mathrm{C}_{6}$ carbides, and of austenite, are summarized in Table $2[15,21]$. In the as-cast condition, $\mathrm{M}_{7} \mathrm{C}_{3}$ does not have an orientation relationship with the austenitic matrix [19]. The $\mathrm{M}_{23} \mathrm{C}_{6}$ carbides are typically observed to have a cube-cube orientation relationship with the matrix [19, 22], the same crystal structure and a lattice parameter almost exactly three times that of the matrix. No orientation relationship between the $\mathrm{M}_{7} \mathrm{C}_{3}$ carbides that transform from $\mathrm{M}_{23} \mathrm{C}_{6}$ as a result of carburization and the matrix has been reported.

Based on the orientation results and information in literature, there are a number of possible options for the formation of the austenite regions that appear contained by the $\mathrm{M}_{7} \mathrm{C}_{3}$ carbides:

- If the austenite regions are individual precipitates separate from the matrix:

- If $\mathrm{M}_{7} \mathrm{C}_{3}$ in the carburized condition has no rational OR with the austenitic matrix, then the austenite regions must have nucleated in $\mathrm{M}_{23} \mathrm{C}_{6}$ or at the transformation front. A schematic portraying how this may occur at the transformation front is seen in Fig. 10(a).

- If $\mathrm{M}_{7} \mathrm{C}_{3}$ in the carburized condition does have a rational $\mathrm{OR}$ with the matrix, the austenite regions may gain an $\mathrm{OR}$ by having $\mathrm{M}_{7} \mathrm{C}_{3}$ present at the point of nucleation. Nucleation could occur at or behind the transformation front.

- The decomposition of $\mathrm{M}_{23} \mathrm{C}_{6}$ may begin at the $\mathrm{M}_{23} \mathrm{C}_{6} /$ austenite interface with growth of existing austenite cooperatively with $\mathrm{M}_{7} \mathrm{C}_{3}$. In this case, the austenitic regions that appear contained by the $\mathrm{M}_{7} \mathrm{C}_{3}$ carbides would be expected to be connected to the matrix in three dimensions. It is possible that the twin growth direction may be more favorable than the normal growth direction in some cases. A schematic of how the austenite matrix may grow cooperatively with $\mathrm{M}_{7} \mathrm{C}_{3}$ is shown in Fig. 10(b).

From the deep etching results, it seems more likely that the austenite regions that appear contained by the $\mathrm{M}_{7} \mathrm{C}_{3}$ carbides are connected to the matrix in three dimensions, as opposed to being individual precipitates separate from the matrix. The gaps in between the $\mathrm{M}_{7} \mathrm{C}_{3}$ carbide grains after deep etching appear more prevalent closer to the transition than at near the inner diameter, as do the austenite regions that appear contained by the carbides in the as-polished condition. It is possible that the contained austenite regions are the gaps in between the grains, and appear contained by the $\mathrm{M}_{7} \mathrm{C}_{3}$ carbides due to sectioning effects.

\section{$\mathrm{Cr}-\mathrm{Ni}-\mathrm{Nb}-\mathrm{Si}$ Rich Phase}

In the 3.5-7.2 mm region of the wall, a phase rich in silicon, nickel, niobium, and chromium was observed, with a light gray contrast in BSE images in comparison to the darker gray chromium carbides. The average composition measured by EDS is shown in Fig. 11. The $\mathrm{Cr}-\mathrm{Ni}-\mathrm{Nb}-\mathrm{Si}$ rich phase appeared to be transformed from $\mathrm{NbC}$, and the area covered by this phase appeared to increase as distance from the inner diameter increased. 


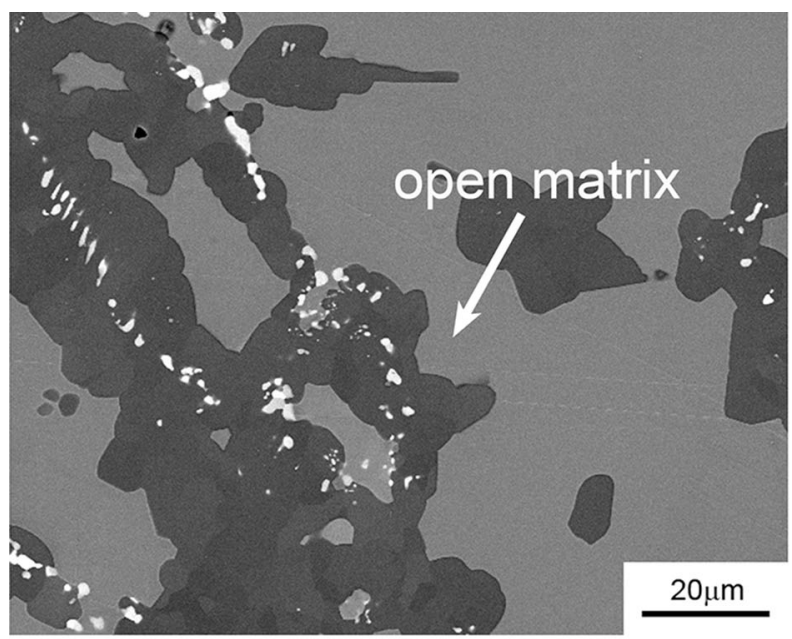

(a)

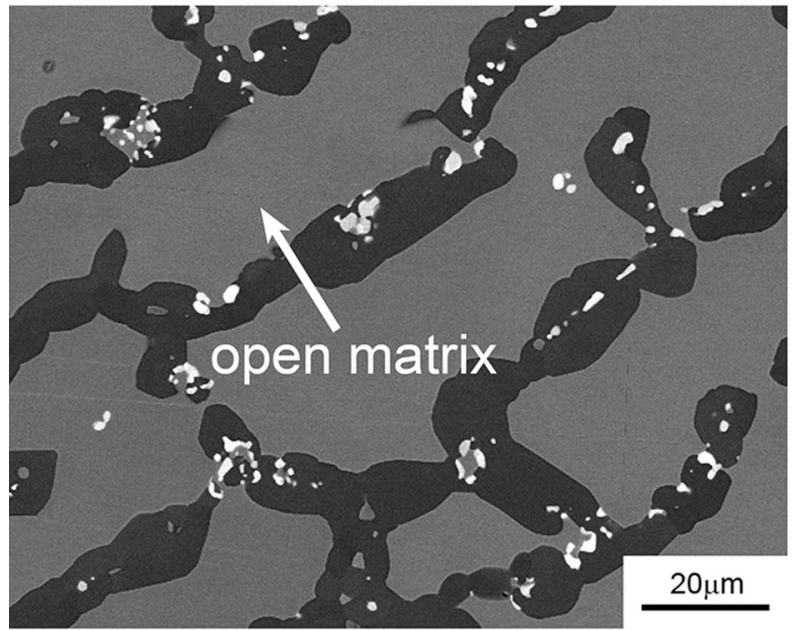

(c)

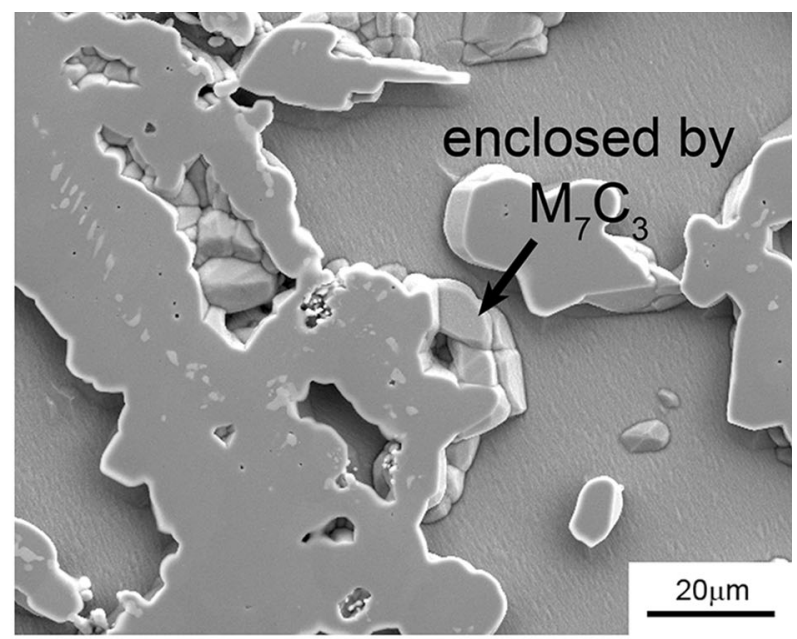

(b)

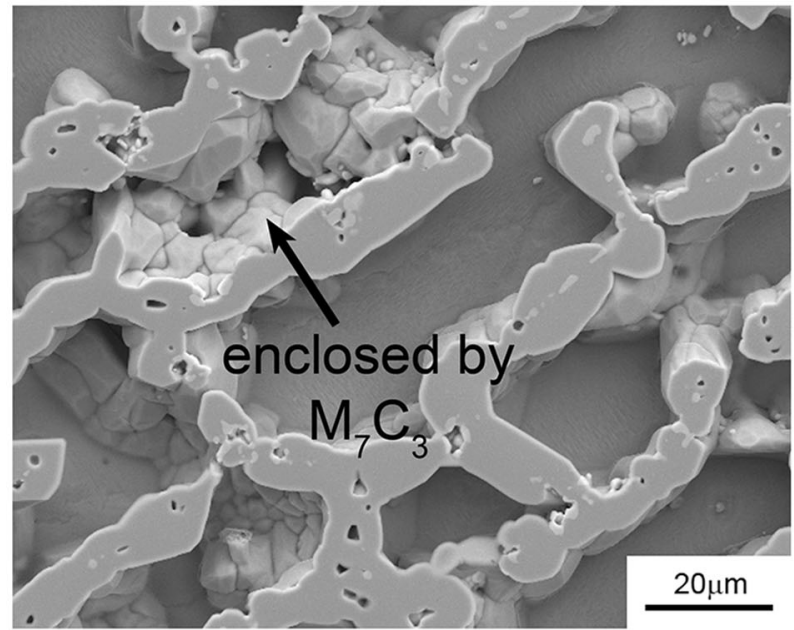

(d)

Fig. $7 \mathrm{M}_{7} \mathrm{C}_{3}$ carbides (a) and (b) $1.0 \mathrm{~mm}$ from the inner diameter, as polished (BSE) and after 30 min in glyceregia (SEI) respectively. (c) and (d) $3.0 \mathrm{~mm}$ from the inner diameter, as polished (BSE) and after $120 \mathrm{~min}$ in glyceregia (SEI) respectively

The instability of $\mathrm{NbC}$ precipitates at temperatures of $700-1050{ }^{\circ} \mathrm{C}$ has been well reported in the literature $[1$, 22-27]. The product of the transformation is generally identified as G-phase, which has a commonly reported composition of $\mathrm{Ni}_{16} \mathrm{Nb}_{6} \mathrm{Si}_{7}$, and an FCC structure with a lattice parameter of $1.12 \mathrm{~nm}[1,23,24]$.

The transformed phase identified in the ex-service tube contained $\mathrm{Nb}, \mathrm{Ni}$, and $\mathrm{Si}$. However, it also contained a significant amount of chromium (determined by EDS as 42.5 at.\%), and the $\mathrm{Ni}$ content was significantly lower (32.5 at.\%), than the values typically reported for G-phase (approximately 55 at.\%).

Another phase, the diamond cubic $\eta$-carbide, has also been identified in ex-service $\mathrm{HP}-\mathrm{Nb}$ reformer tubes and aged HP-Nb alloy [10, 22, 25-27]. The typical composition of the transformed phase in the ex-service pyrolysis tube closely resembled the reported compositions. Despite ambiguity in the EBSD analysis due to the similar space groups and lattice parameters of G-phase and $\eta$-carbide, the comparison between the composition of the transformed phase (Fig. 11) to reported values was considered sufficient evidence to identify the transformed phase in the ex-service tube as $\eta$-carbide, as opposed to G-phase. As $\eta$ carbide contains a significant amount of chromium, it is likely that the NbC-to- $\eta$-carbide transformation contributes to the chromium depletion of the matrix.

The current literature on the NbC-to-G-phase and NbCto- $\eta$-carbide transformations in $\mathrm{HP}-\mathrm{Nb}$ alloys is constrained to ex-service reformer tubes $[8,22,25-27]$ and a limited number of laboratory-aged studies [1, 23-25]. Based on the available literature and data from laboratoryaged HP-Nb alloys, Buchanan [10] concluded that the NbC-to-G-phase and NbC-to- $\eta$-carbide transformations in aged $\mathrm{HP}-\mathrm{Nb}$ alloys are dictated by the aging temperature. 


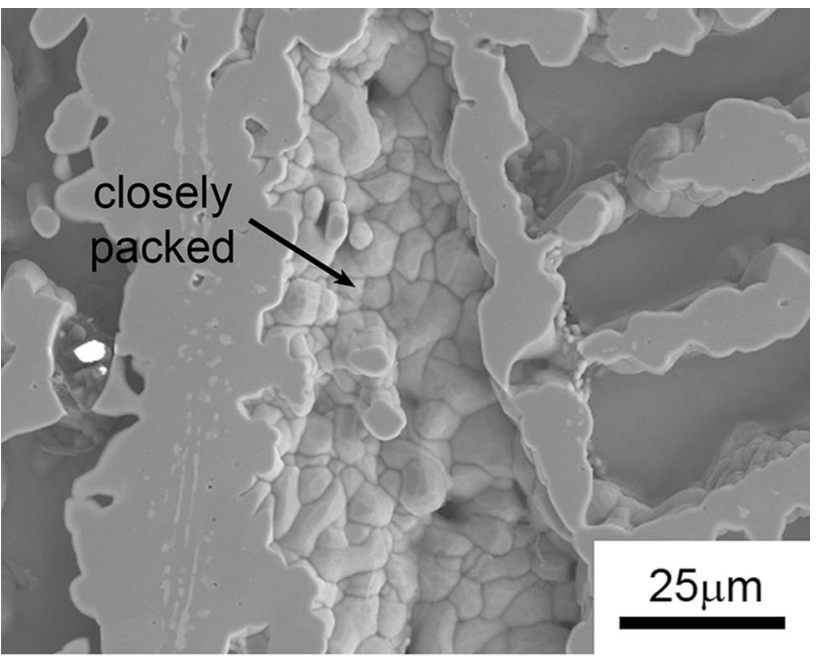

(a)

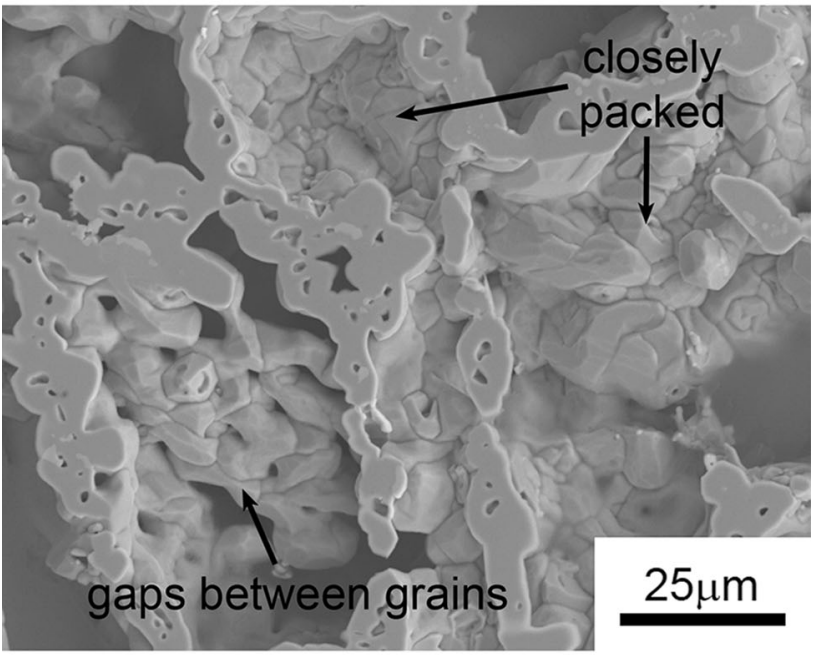

(b)

Fig. 8 SEI images of $\mathrm{M}_{7} \mathrm{C}_{3}$ carbides at (a) inner diameter region and (b) inner diameter side of the $\mathrm{M}_{7} \mathrm{C}_{3} / \mathrm{M}_{23} \mathrm{C}_{6}$ transition after $180 \mathrm{~min}$ in glyceregia

At temperatures below $875{ }^{\circ} \mathrm{C}$ the NbC-to-G-phase transformation dominates. Between 875 and $920{ }^{\circ} \mathrm{C}$, the $\mathrm{NbC}$ to-G-phase and NbC-to- $\eta$-carbide transformations can occur in parallel, and the $\eta$-carbide volume fraction is expected to increase with aging temperature until the $\mathrm{NbC}$ to- $\eta$-carbide transformation becomes dominant, up to an upper limit of $1050{ }^{\circ} \mathrm{C}$ above which $\mathrm{NbC}$ carbides are stable.

As a result of carburization during service, the pyrolysis tube has a continual composition gradient across the tube wall (both for the austenitic matrix and the $\mathrm{M}_{7} \mathrm{C}_{3}$ carbides), and has a phase transformation front where $\mathrm{M}_{23} \mathrm{C}_{6}$ transforms to $\mathrm{M}_{7} \mathrm{C}_{3}$, along with microstructural changes (such as the instability of $\mathrm{NbC}$ ) associated with long term aging. There is also significant coarsening of the carbides in

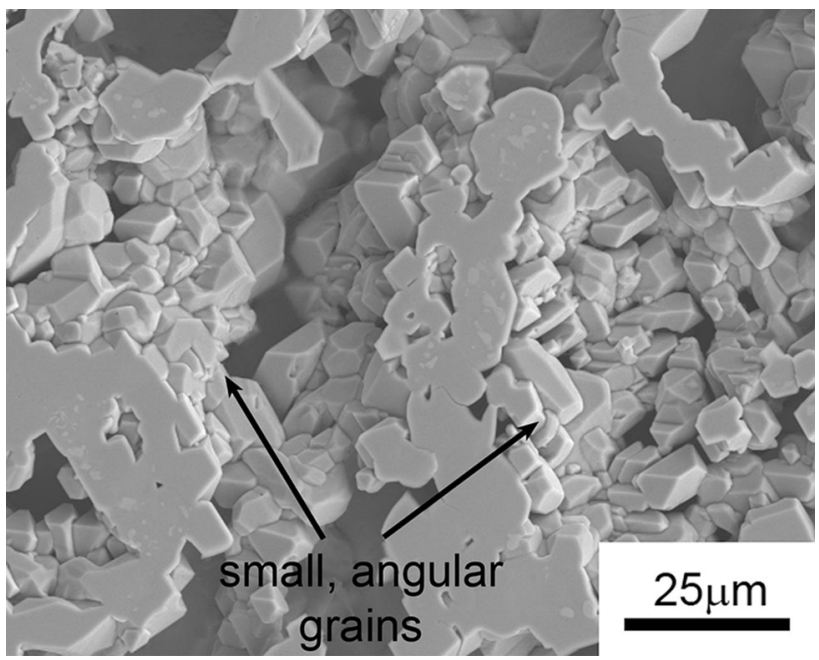

Fig. 9 SEI image of $\mathrm{M}_{23} \mathrm{C}_{6}$ carbides on the outer diameter side of the $\mathrm{M}_{7} \mathrm{C}_{3} / \mathrm{M}_{23} \mathrm{C}_{6}$ transition, after $180 \mathrm{~min}$ in glyceregia

highly carburized areas of the tube wall. The combination of these factors creates significantly different conditions within the pyrolysis tube compared to ex-service reformer tubes and laboratory-aged alloys. It is highly likely that the difference in conditions results in the temperature ranges over which the NbC-to-G-phase and NbC-to- $\eta$-carbide transformation occur in pyrolysis tubes to differ from those seen in the ex-service reformer tubes and laboratory aged alloys. This is evidenced by the ex-service pyrolysis tube's service temperature of $704{ }^{\circ} \mathrm{C}$, along with the presence of $\eta$-carbide and lack of G-phase in the microstructure.

\section{Inner and Outer Oxide Scales, Carbonitrides}

At the inner diameter of the tube, a chromium-rich oxide scale with a depth of $100 \mu \mathrm{m}$ was present. Inwards of the chromium oxide scale, a band of dendritic silicon oxides 250-300- $\mu \mathrm{m}$ thick penetrated into the tube (Fig. 12). Within this band, no chromium-rich precipitates were found, with only $\mathrm{NbC}$ carbides identified.

An oxide scale was also present at the outer diameter, with a layer composed of chromium oxides and silicon oxides $100-150-\mu \mathrm{m}$ thick. The silicon oxides penetrated into the tube across a band $200-300-\mu \mathrm{m}$ thick. This band was also free of chromium-rich precipitates (Fig. 13) with only $\mathrm{NbC}$ carbides present.

The presence of a chromium-rich oxide scale results in the depletion of chromium in the matrix adjacent to the scale, leading to a $\mathrm{Cr}$-depleted zone free of chromium-rich precipitates. The $\mathrm{Cr}-$ and Si-rich oxide scales and the chromium precipitate free zone that were observed at the inner and outer diameters of the ex-service tube are consistent with observations of HP alloys exposed to oxidizing and carburizing environments at elevated temperatures [28, 29]. 
Table 2 Space groups and lattice parameters of relevant chromium carbides and the austenitic matrix $[15,21]$

\begin{tabular}{lll}
\hline Phase & Space group & Lattice parameter \\
\hline $\mathrm{M}_{7} \mathrm{C}_{3}$ & Pnma & $a=0.453 \mathrm{~nm}, b=0.701 \mathrm{~nm}, c=1.21 \mathrm{~nm}$ \\
$\mathrm{M}_{23} \mathrm{C}_{6}$ & $\mathrm{Fm} \overline{3} \mathrm{~m}$ & $a=1.066 \mathrm{~nm}$ \\
Austenite & $\mathrm{Fm} \overline{3} \mathrm{~m}$ & $a=0.366 \mathrm{~nm}$ \\
\hline
\end{tabular}

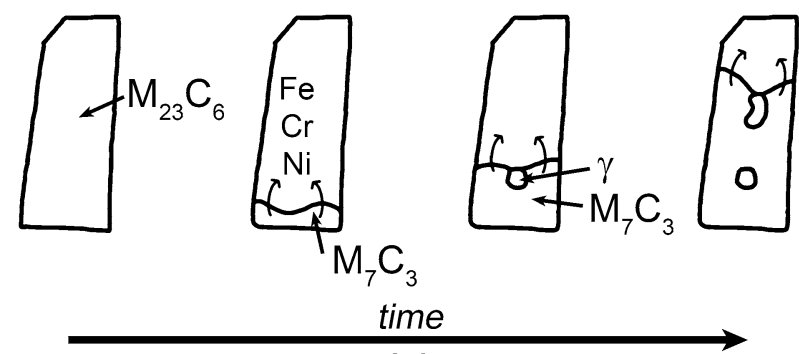

(a)
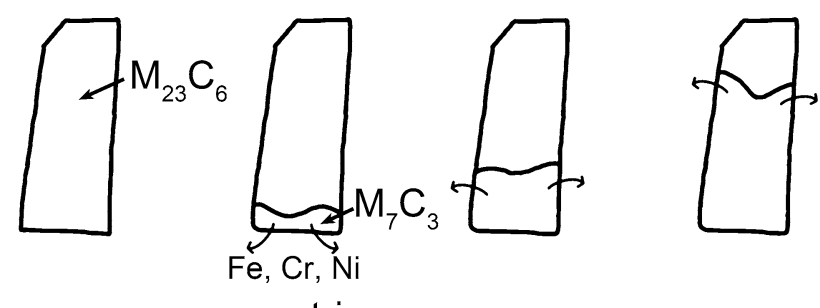

$\gamma$ matrix

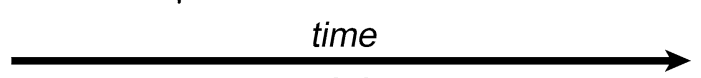

(b)

Fig. 10 (a) Schematic of how austenite may precipitate as individual precipitates at the $\mathrm{M}_{7} \mathrm{C}_{3} / \mathrm{M}_{23} \mathrm{C}_{6}$ transformation front, (b) schematic of how the austenite matrix may grow cooperatively with $\mathrm{M}_{7} \mathrm{C}_{3}$ at the $\mathrm{M}_{7} \mathrm{C}_{3} / \mathrm{M}_{23} \mathrm{C}_{6}$ transformation front

Inwards from the chromium-rich precipitate free zone at the outer diameter, the $\mathrm{M}_{23} \mathrm{C}_{6}$ carbides in the carbide network transformed into a different chromium-rich precipitate, which had a blocky appearance and a darker contrast in $\mathrm{BSE}$ images compared to the medium gray $\mathrm{M}_{23} \mathrm{C}_{6}$ carbides. Lath-shaped precipitates of the same contrast were observed to have precipitated intragranularly. Both the lath-shaped precipitates and the blocky precipitates transformed from $\mathrm{M}_{23} \mathrm{C}_{6}$ were identified as $\mathrm{Cr}_{2}(\mathrm{C}, \mathrm{N})$, a carbonitride. It appeared that the majority of the $\mathrm{M}_{23} \mathrm{C}_{6}$ within a narrow band of $<200 \mu \mathrm{m}$ had transformed into $\mathrm{Cr}_{2}(\mathrm{C}, \mathrm{N})$, with some of the $\mathrm{M}_{23} \mathrm{C}_{6}$ carbides further into the tube having also transformed into $\mathrm{Cr}_{2}(\mathrm{C}, \mathrm{N})$ (Fig. 13). The transformation of $\mathrm{M}_{23} \mathrm{C}_{6}$ to $\mathrm{Cr}_{2}(\mathrm{C}, \mathrm{N})$ and the precipitation of $\mathrm{Cr}_{2}(\mathrm{C}, \mathrm{N})$ at the outer diameter of the tube occurs due to the exposure of the tube's outer surface to the flue gases present in the furnace during service. Nitrogen diffusion into the tube results in the precipitation of $\mathrm{Cr}_{2}(\mathrm{C}, \mathrm{N})$ and the conversion of $\mathrm{M}_{23} \mathrm{C}_{6}$ to $\mathrm{Cr}_{2}(\mathrm{C}, \mathrm{N})$, which can then continue to grow by uptake of chromium and nitrogen [3]. The

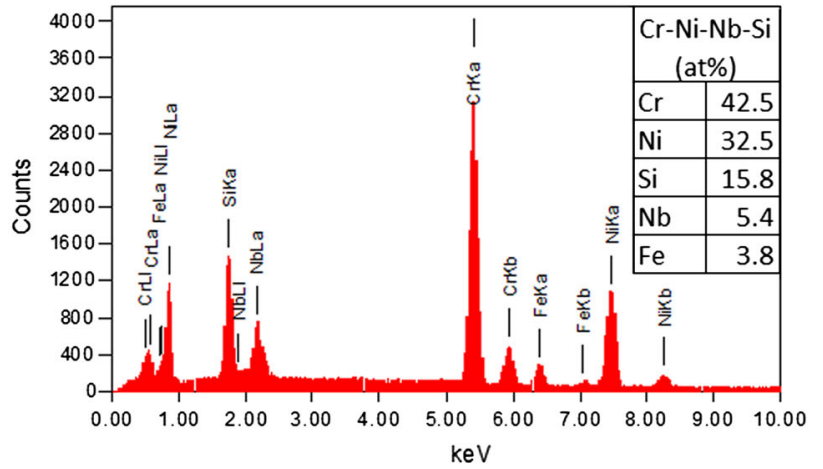

(a)

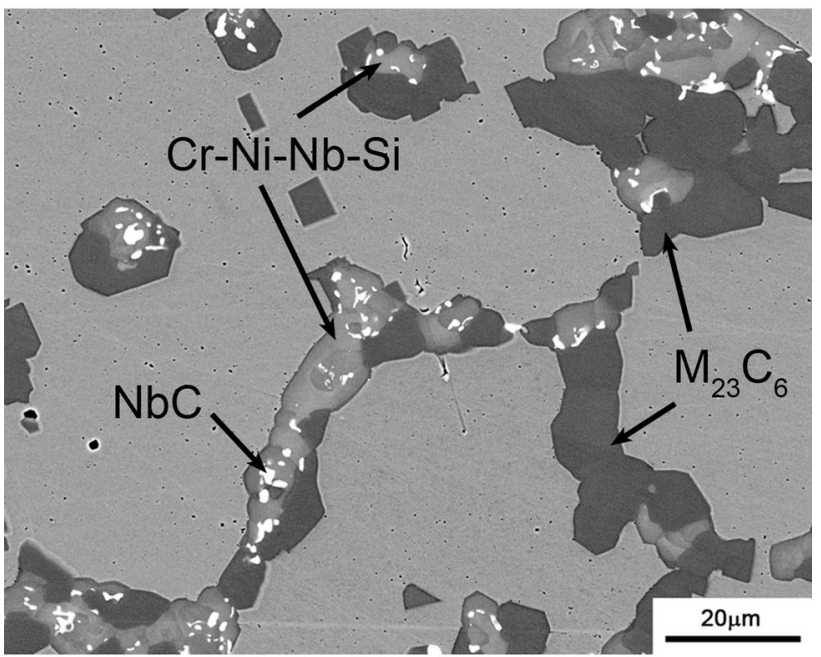

(b)

Fig. 11 (a) typical composition of the $\mathrm{Cr}-\mathrm{Ni}-\mathrm{Nb}-\mathrm{Si}$ rich phase as determined by EDS, (b) BSE micrograph showing the transformation of $\mathrm{NbC}$ to a $\mathrm{Cr}-\mathrm{Ni}-\mathrm{Nb}-\mathrm{Si}$ rich phase

changes in materials properties due to nitriding are very similar to those due to carburization-in both cases precipitates are formed, internal volume is increased, and the matrix is depleted of chromium [3].

$\mathrm{Cr}_{2}(\mathrm{C}, \mathrm{N})$ precipitates were also identified at the $\mathrm{M}_{7} \mathrm{C}_{3} /$ $\mathrm{M}_{23} \mathrm{C}_{6}$ transformation front. They appeared to take the place of the $\mathrm{M}_{7} \mathrm{C}_{3}$ carbides in the network, as indicated in Fig. 5, and were not seen anywhere else in the mid-wall region of the sample. It is currently unknown why $\mathrm{Cr}_{2}(\mathrm{C}, \mathrm{N})$ precipitates are present at such a distance from the $\mathrm{M}_{23} \mathrm{C}_{6} /$ $\mathrm{Cr}_{2}(\mathrm{C}, \mathrm{N})$ transformation front, and why they are not present anywhere else in the region between the $M_{7} C_{3} / M_{23} C_{6}$ 


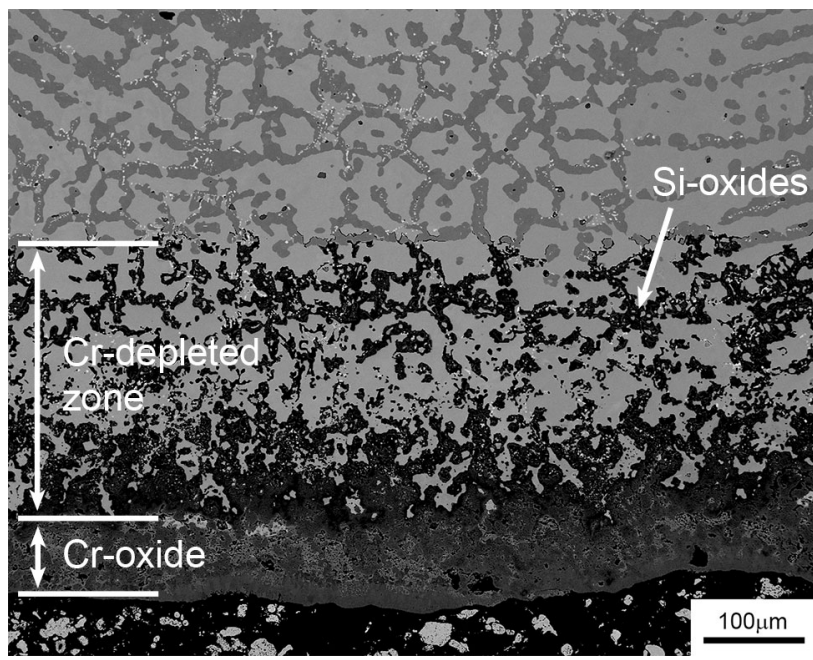

Fig. 12 BSE micrograph of oxide scale at inner diameter

transformation front and the outer diameter. However, due to the similar effects on mechanical properties of nitrides and carbides [3], it is unlikely that the replacement of some carbides by carbonitrides in the inner wall has any significant effect on the tube properties.

\section{Chromium Depletion in the Matrix and the Paramagnetic to Ferromagnetic Change}

In the as-cast condition, HP alloy tubes are paramagnetic. The precipitation and growth of chromium carbides causes chromium depletion in the austenitic matrix. With increasing carburization, the matrix composition tends toward the binary $\mathrm{Fe}-\mathrm{Ni}$ composition, and the matrix becomes progressively more ferromagnetic $[2,5,7,30-32]$.

The change in matrix chromium content, measured at a distance of $10 \mu \mathrm{m}$ from the primary chromium carbide network, is shown in Fig. 14. The matrix chromium content is significantly below the typical as-cast chromium content of $25 \mathrm{wt} \%$, particularly at the inner wall region. The location of the $\mathrm{M}_{7} \mathrm{C}_{3} / \mathrm{M}_{23} \mathrm{C}_{6}$ transformation front corresponded with a matrix chromium content of 11-12 wt \% .

The change in matrix composition across the tube wall has been plotted on the ternary $\mathrm{Fe}-\mathrm{Cr}-\mathrm{Ni}$ diagram (Fig. 15) along with data representing the paramagnetic and ferromagnetic compositions (determined by the Curie temperature) [33-35]. As seen in Fig. 15, the matrix composition is in the ferromagnetic region across the entire tube wall. Although the $\mathrm{M}_{7} \mathrm{C}_{3} / \mathrm{M}_{23} \mathrm{C}_{6}$ transformation front, which is sometimes used as a measure of the depth of carburization [5], is only located at a distance of approximately $5 \mathrm{~mm}$ from the inner diameter, the large, blocky $\mathrm{M}_{23} \mathrm{C}_{6}$ carbides in the 5-7.2 mm wall region and the regions of chromiumrich $\eta$-carbide in the $3.5-7.2 \mathrm{~mm}$ wall region have likely

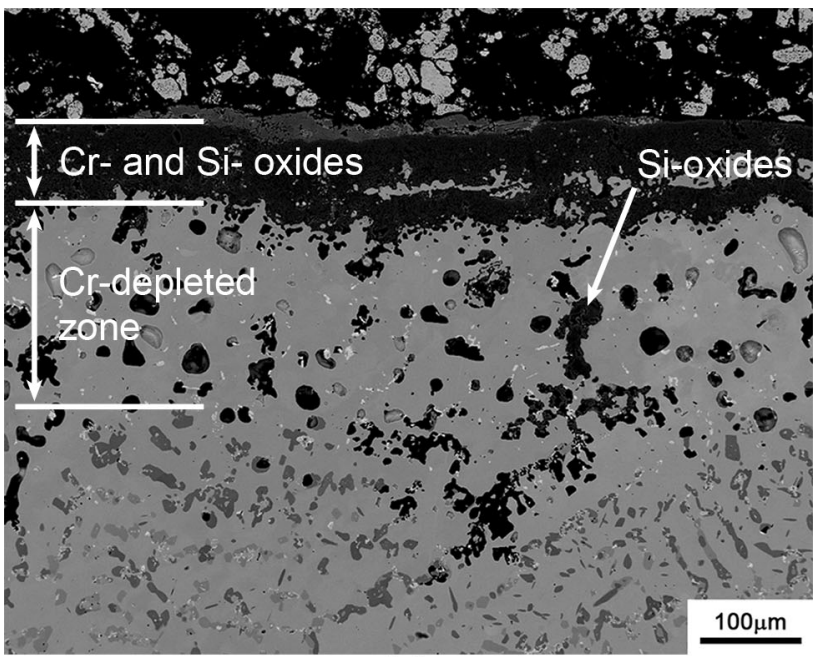

(a)

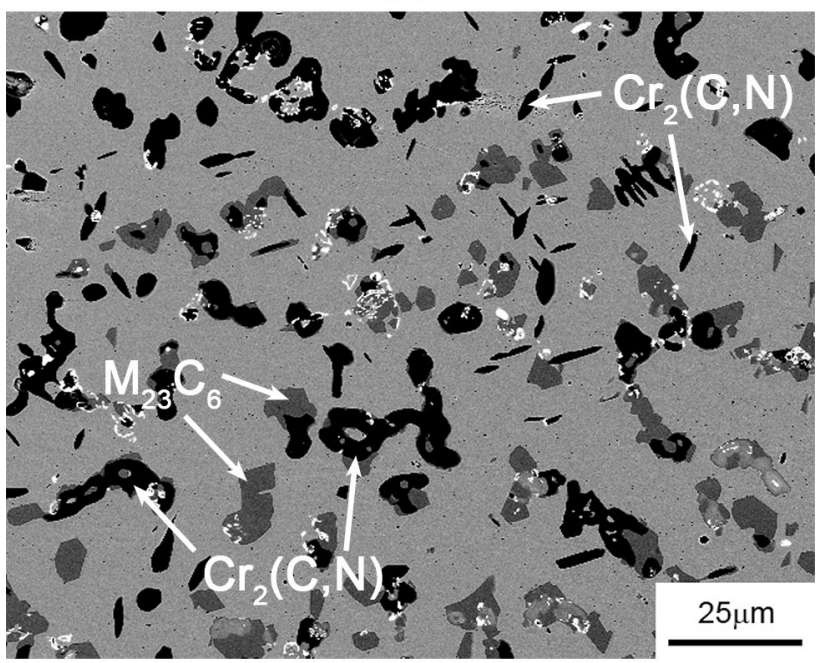

(b)

Fig. 13 BSE micrographs of the outer diameter indicating (a) the $\mathrm{Cr}$ depleted zone, and (b) intragranular $\mathrm{Cr}_{2}(\mathrm{C}, \mathrm{N})$ and the transformation of $\mathrm{M}_{23} \mathrm{C}_{6}$ into $\mathrm{Cr}_{2}(\mathrm{C}, \mathrm{N})$

contributed to the chromium depletion of the matrix at the outer wall region, leading to a matrix composition that is ferromagnetic at room temperature.

\section{NACE Etching Method}

A dark etching band was clearly seen on the sample that was subjected to the NACE etching method (Fig. 16a). The etching band extended a depth of 5-5.5 $\mathrm{mm}$ from the inner diameter, which the standard states indicates the depth of the carburized region [11].

The location where the matrix chromium content reached 11-12 wt \% corresponded with both the location of the $\mathrm{M}_{7} \mathrm{C}_{3}$ / $\mathrm{M}_{23} \mathrm{C}_{6}$ transformation front (approximately $5 \mathrm{~mm}$ from the inner diameter) and the edge of the NACE etching band. 


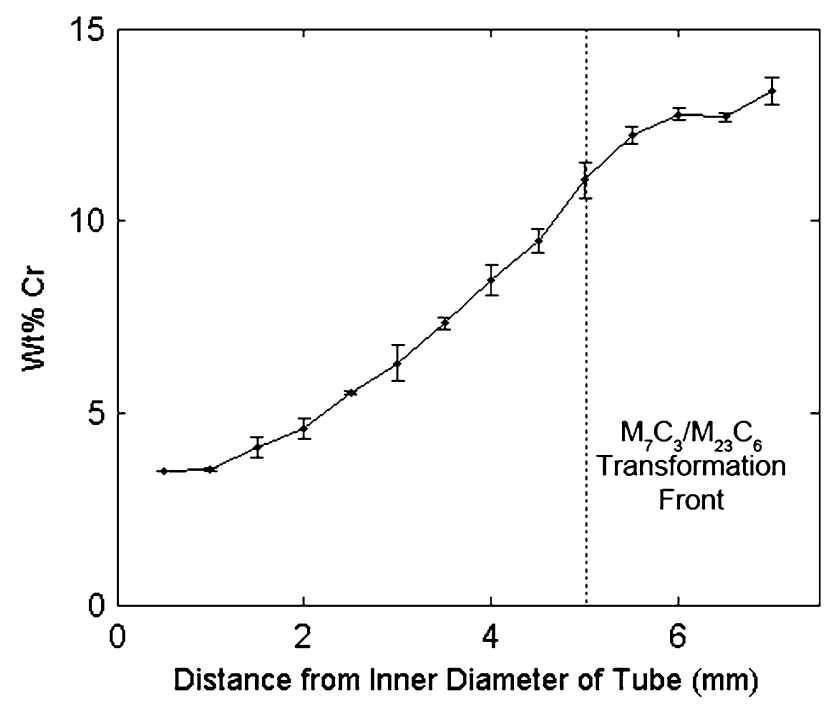

Fig. 14 Chromium content of the matrix across the tube wall, as determined by EDS. Results from three EDS spectra were averaged at each location

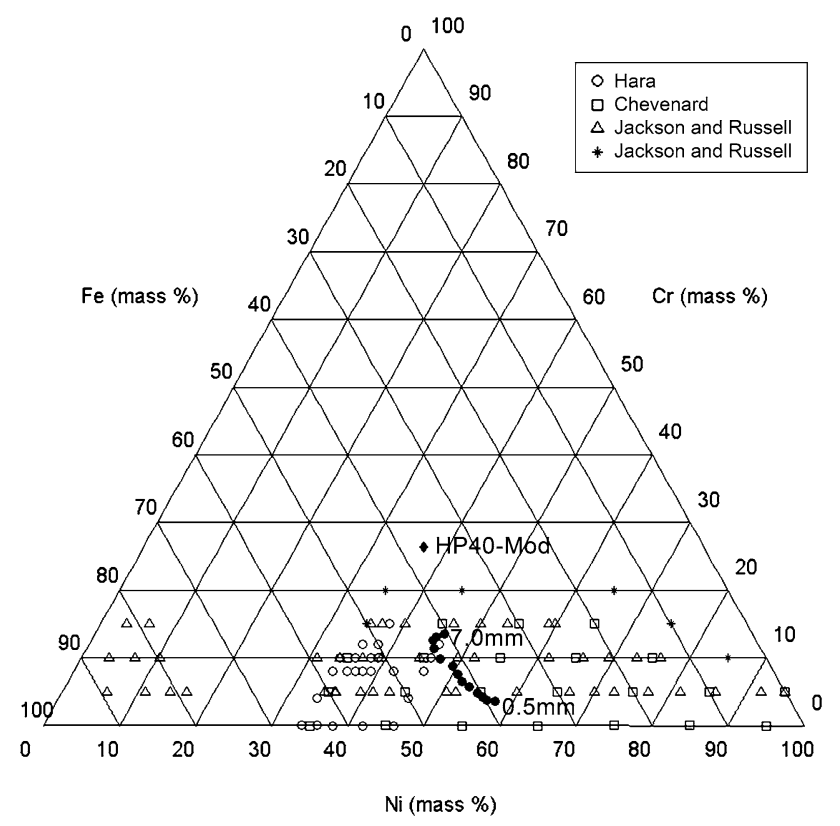

Fig. 15 Ternary $\mathrm{Fe}-\mathrm{Cr}-\mathrm{Ni}$ diagram showing the changes in matrix composition of the ex-service tube. Typical as-cast condition of HP40-Mod is denoted by a solid diamond. Matrix compositions are denoted by solid circles, and labeled with distance $(\mathrm{mm})$ from the inner diameter. Asterisks denote compositions that are paramagnetic at room temperature. Open circles, squares, and triangles denote compositions that are ferromagnetic at room temperature

Two other ex-service HP alloy ethylene pyrolysis tubes (tubes B and C) were also subjected to the NACE etch for comparison with the ex-service tube for which the microstructure has been characterized (tube A).

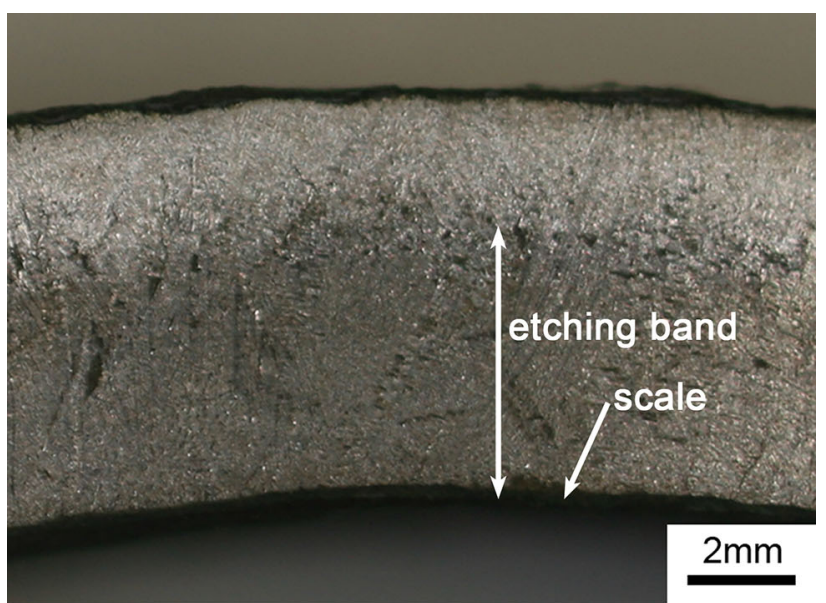

(a)

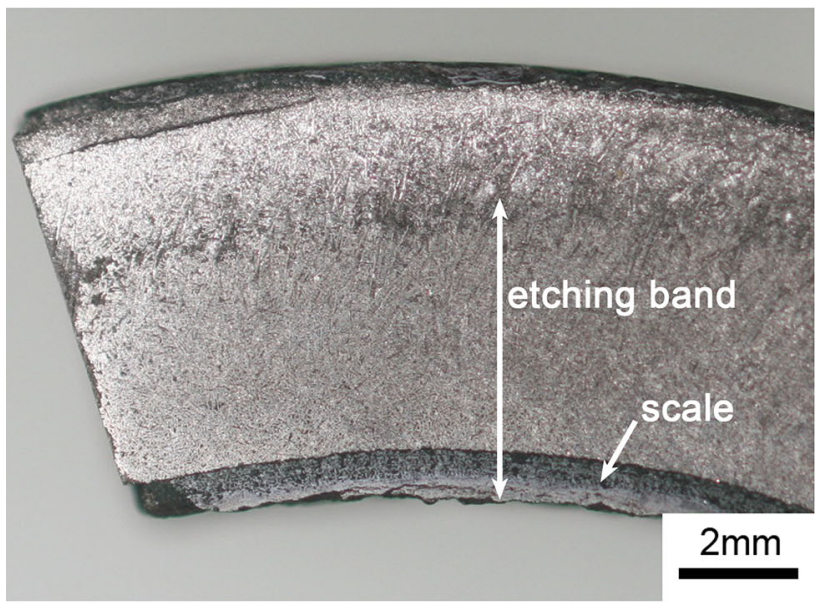

(b)

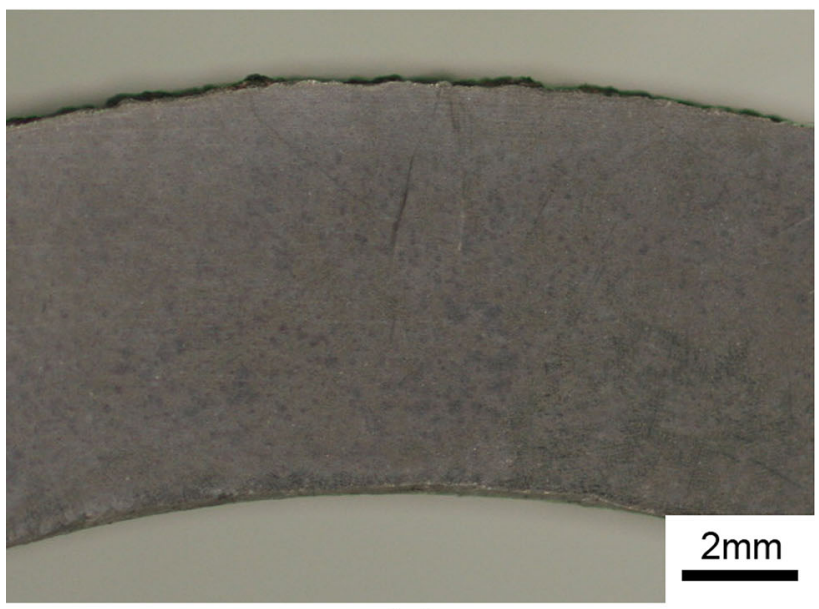

(c)

Fig. 16 Sections of (a) tube A, (b) tube B, and (c) tube C after being subjected to the NACE etching method

The microstructure of tube B appeared very similar to tube A with regards to phases present and morphologies. However, tube B did not contain $\eta$-carbide or G-phase, and 
the $\mathrm{M}_{7} \mathrm{C}_{3} / \mathrm{M}_{23} \mathrm{C}_{6}$ transition occurred closer to the inner diameter $(4 \mathrm{~mm})$. The microstructure of tube $\mathrm{C}$ appeared similar to that of as-cast HP alloys, however, the $\mathrm{NbC}$ carbides appeared to have fully transformed into G-phase.

The etching results for tubes $\mathrm{B}$ and $\mathrm{C}$ are shown in Fig. 16(b) and (c), respectively. It was seen that tube B displayed an etching band as a result of the NACE etch, however, it was not as well-defined as that of tube A, and did not extend as far into the tube wall. The etched surface of tube $\mathrm{C}$ appeared dull compared to the as-polished condition but was otherwise unaffected by the NACE etchant.

It should be noted that the NACE standard states that the contrast is achieved by the attack of carbides, however, the present results indicate that the contrast is due to attack of the austenitic matrix where the chromium content falls below approximately $12 \mathrm{wt} \%$.

\section{Eddy Current NDT Response}

The eddy current NDT response of tubes A, B, and C, as measured by the carburization crawler under development at Quest integrity NZL Ltd, is shown in Fig. 17, where the normalized probe inductance is plotted against frequency. Tube A displays the highest normalized probe inductance across all frequencies, ranging from 1.83 at low frequencies to 1.57 at higher frequencies. A high normalized probe inductance across all frequencies indicates that the entire tube wall is highly carburized, which is consistent with the matrix of tube A being ferromagnetic across the entire tube wall as indicated by the matrix composition profile. The slight drop in normalized probe inductance at high frequencies indicates the outer wall region is carburized to a slightly lesser extent than the inner wall, which is consistent with microstructural observations and the NACE etch results.

Tube B displays the same trend in normalized probe inductance as tube A, albeit at a slightly lower range, indicating that tube $\mathrm{B}$ is less carburized than tube $\mathrm{A}$, which is consistent with the $\mathrm{M}_{7} \mathrm{C}_{3} / \mathrm{M}_{23} \mathrm{C}_{6}$ transition occurring closer to the inner diameter in tube $\mathrm{B}$, and the lack of $\eta$-carbide to contribute to the chromium depletion. The normalized probe inductance for tube B ranges from 1.72 at low frequencies to 1.50 at high frequencies. The eddy current response of tube $\mathrm{B}$ indicates carburization to a lesser extent than tube $\mathrm{A}$, and correlates well to the NACE etch results.

Tube $\mathrm{C}$ exhibits a constant normalized probe inductance of 1.02 across all frequencies. An un-carburized tube would be expected to have a normalized probe inductance below that of the probe in air, i.e., $<1$. The response of tube $\mathrm{C}$ indicates that there is little or no carburization. Tube $\mathrm{C}$ did not respond to the NACE etchant, and did not display a chromium carbide transition in the microstructure, which is consistent with little or no carburization, however, slight carbide coarsening may have caused chromium depletion

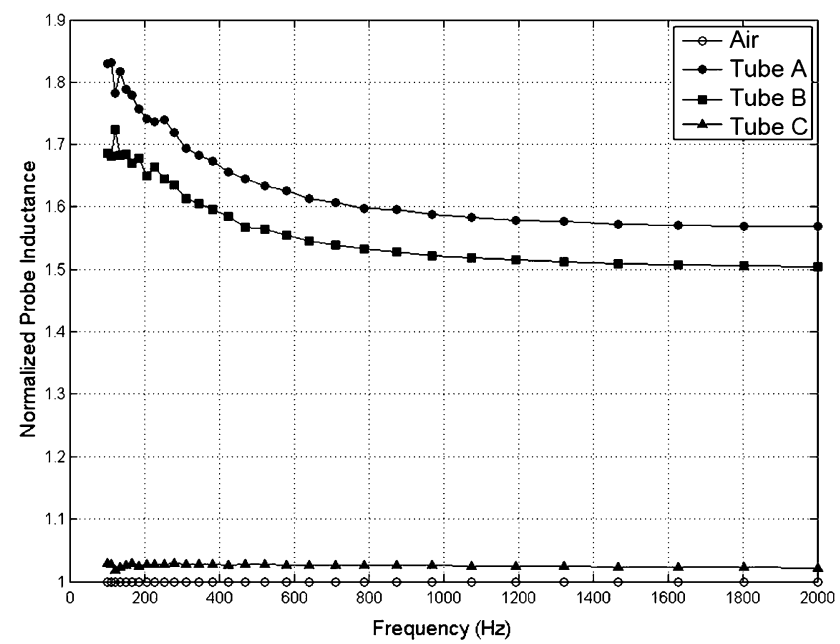

Fig. 17 Eddy current NDT response (normalized probe inductance vs. frequency) of tubes $\mathrm{A}, \mathrm{B}$, and $\mathrm{C}$

in the matrix, leading to a normalized inductance value slightly greater than 1 .

\section{Conclusions}

- Three important phase transformations were identified in the ex-service HP alloy tube:

- $\mathrm{M}_{23} \mathrm{C}_{6}$ transformed to $\mathrm{M}_{7} \mathrm{C}_{3}$, with the transformation front located a distance of approximately $5 \mathrm{~mm}$ from the inner diameter.

- $\mathrm{M}_{23} \mathrm{C}_{6}$ transformed to $\mathrm{Cr}_{2}(\mathrm{C}, \mathrm{N})$ at the outer diameter of the tube, as a result of exposure of the tube's outer surface to flue gases during service. $\mathrm{Cr}_{2}(\mathrm{C}, \mathrm{N})$ carbonitrides were also observed at the $\mathrm{M}_{7} \mathrm{C}_{3} /$ $\mathrm{M}_{23} \mathrm{C}_{6}$ transformation front, appearing to take the place of $\mathrm{M}_{7} \mathrm{C}_{3}$ carbides, but their presence at the transformation front is currently unexplained.

- $\mathrm{NbC}$ transformed to $\eta$-carbide in the 3.5-7.2 mm region of the wall. $\eta$-carbide was identified rather than G-phase due to significant differences in the chromium and nickel content between the two phases. As $\eta$-carbide contains a significant amount of chromium, it is likely that the NbC-to- $\eta$-carbide transformation contributes to the chromium depletion of the matrix. Although there is information in literature regarding the temperature ranges over which the $\mathrm{NbC}$-to-G-phase and $\mathrm{NbC}$-to- $\eta$-carbide transformations occur in HP-Nb alloys, the conditions under which these data were collected differ significantly from the carburizing conditions experienced by pyrolysis tubes in service, so are not directly comparable. 
- The $\mathrm{M}_{7} \mathrm{C}_{3}$ carbides appeared to contain a separate phase, identified as austenite. EBSD analysis on contained austenite-matrix pairs determined that $69 \%$ of the pairs obtained an orientation typical of a cubecube orientation, and 18\% obtained an orientation typical of a twin orientation. Deep etching in glyceregia showed the $\mathrm{M}_{7} \mathrm{C}_{3}$ carbides appeared to be composed of many rounded grains, and that regions of austenite that appeared as open matrix in the as-polished condition would have appeared enclosed by the $\mathrm{M}_{7} \mathrm{C}_{3}$ carbides had the plane of polish been deeper into the sample. It seems likely that the austenite regions that appear contained by the $\mathrm{M}_{7} \mathrm{C}_{3}$ carbides are actually connected to the matrix in three dimensions, and may appear contained as a result of sectioning effects.

- The edge of the NACE etching band corresponds to the $\mathrm{M}_{23} \mathrm{C}_{6} / \mathrm{M}_{7} \mathrm{C}_{3}$ transformation front, which corresponded with a matrix chromium content of approximately $12 \mathrm{wt} \%$. Rather than attack of carbides, it appears that the NACE etch contrast occurs due to attack of the austenitic matrix where the chromium content falls below approximately $12 \mathrm{wt} \%$.

- Severe chromium depletion of the matrix was seen across the tube wall, but particularly near the inner diameter region where the matrix chromium content dropped as low as $4 \mathrm{wt} \%$. A comparison with Curie Temperature data indicated that the matrix is ferromagnetic across the entire tube wall.

- The present results indicate that the eddy current method is able to detect and measure carburization nondestructively.

Acknowledgments The authors gratefully acknowledge the financial support of Quest Integrity NZL Limited, and the Ministry of Science and Innovation of New Zealand (now administered by Callaghan Innovation) under contract QINZ1001. Thanks to Charles Thomas and Andy Saunders-Tack of Quest Integrity NZL Ltd for their continued support.

\section{References}

1. G.D. de Almeida Soares, L.H. de Almeida, T.L. da Silveira, I. Le May, Niobium additions in HP heat-resistant cast stainless steels. Mater. Charact. 29, 387-396 (1992)

2. I.C. Silva, J.M.A. Rebello, A.C. Bruno, P.J. Jacques, B. Nysten, J. Dille, Structural and magnetic characterization of a carburized cast austenitic steel. Scripta Mater. 59, 1010-1013 (2008)

3. D. Jakobi, R. Gommans, Typical failures in pyrolysis coils for ethylene cracking. Mater. Corros. 54, 881-886 (2003)

4. A.A. Kaya, Microstructure of HK40 alloy after high-temperature service in oxidizing/carburizing environment. II. Carburization and carbide transformations. Mater. Charact. 49, 23-34 (2002)

5. E. Lang, J. Norton, Monitoring of carburisation by the use of magnetic techniques, Part 1: fundamental aspects and measurements on $25 \mathrm{Cr}$-20Ni steels, Commission of the European Communities, Physical Science, PETTEN, EUR 10566 EN, 1986
6. K.J. Stevens, W.J. Trompetter, Calibration of eddy current carburization measurements in ethylene production tubes using ion beam analysis. J. Phys. D 37, 501-509 (2004)

7. K.J. Stevens, A.J. Tack, C.W. Thomas, D. Stewart, Through-wall carburization detection in ethylene pyrolysis tubes. J. Phys. D 34, 814-822 (2001)

8. S. Shi, J.C. Lippold, Microstructure evolution during service exposure of two cast, heat-resisting stainless steels-HP-Nb modified and 20-32Nb. Mater. Charact. 59, 1029-1040 (2008)

9. K.J. Stevens, A. Parbhu, J. Soltis, Magnetic force microscopy and cross-sectional transmission electron microscopy of carburised surfaces. Curr. Appl. Phys. 4, 304-307 (2004)

10. K.G. Buchanan, The effects of long-term isothermal ageing on the microstructure of $\mathrm{HP}-\mathrm{Nb}$ and HP-NbTi alloys, Doctoral Dissertation, University of Canterbury, Christchurch, 2013

11. NACE International, NACE International Standard Test Method: Evaluation of Carburization of Alloy Tubes Used for Ethylene Manufacture, 2006

12. V. Randle, The Measurement of Grain Boundary Geometry (Institute of Physics Publications, Philadelphia, 1993)

13. X.Q. Wu, H.M. Jing, Y.G. Zheng, Z.M. Yao, W. Ke, Z.Q. Hu, The eutectic carbides and creep rupture strength of $25 \mathrm{Cr} 20 \mathrm{Ni}$ heat-resistant steel tubes centrifugally cast with different solidification conditions. Mater. Sci. Eng. A 293, 252-260 (2000)

14. F.G. Caballero, P. Imizcoz, V. Lopez, L.F. Alvarez, C.G. De Andrés, Use of titanium and zirconium in centrifugally cast heat resistant steel. Mater. Sci. Technol. 23, 528-534 (2007)

15. K.G. Buchanan, M.V. Kral, Crystallography and morphology of niobium carbide in as-cast HP-niobium reformer tubes. Metall. Mater. Trans. A 43, 1760-1769 (2012)

16. A. Schnaas, H.J. Grabke, High-temperature corrosion and creep of $\mathrm{Ni}-\mathrm{Cr}-\mathrm{Fe}$ alloys in carburizing and oxidizing environments. Oxid. Met. 12, 387-404 (1978)

17. H.J. Christ, Experimental characterization and computer-based description of the carburization behaviour of the austenitic stainless steel AISI 304L. Mater. Corros. 49, 258-265 (1998)

18. H.J. Grabke, I. Wolf, Carburization and oxidation. Mater. Sci. Eng. 87, 23-33 (1987)

19. D.J. Young, High Temperature Oxidation and Corrosion of Metals (Elsevier, Amsterdam, 2008)

20. M. Waldenstrom, An experimental study of carbide-austenite equilibria in iron-base alloys with $\mathrm{Mo}, \mathrm{Cr}, \mathrm{Ni}$, and $\mathrm{Mn}$ in the temperature range 1173 to $1373 \mathrm{~K}$. Metall. Trans. A $\mathbf{8 A}$, 1963-1977 (1977)

21. P. Villars, K. Cenzual (ed.), Pearson's Crystal Data: Crystal Structure Database, ASM International, Materials Park, OH (2008)

22. E.A. Kenik, P.J. Maziasz, R.W. Swindeman, J. Cervenka, D. May, Structure and phase stability in a cast modified-HP austenite after long-term ageing. Scripta Mater. 49, 117-122 (2003)

23. R.A.P. Ibanez, G.D. de Almeida Soares, L.H. de Almeida, I. Le May, Effects of Si content on the microstructure of modified-HP austenitic steels. Mater. Charact. 30, 243-249 (1993)

24. L.H. de Almeida, A.F. Ribeiro, I. Le May, Microstructural characterization of modified $25 \mathrm{Cr}-35 \mathrm{Ni}$ centrifugally cast steel furnace tubes. Mater. Charact. 49, 219-229 (2003)

25. K. Nishimoto, K. Saida, M. Inui, M. Takahashi, Changes in microstructure of HP-modified, heat-resisting cast alloys under long-term aging. Repair weld cracking of service-exposed, HPmodified, heat-resisting cast alloys (2nd Report), Welding Research Abroad, 48, 1-9 (2002)

26. C.W. Thomas, K.J. Stevens, M.J. Ryan, Microstructure and properties of alloy HP50-Nb: comparison of as cast and service exposed materials. Mater. Sci. Technol. 12, 469-475 (1996)

27. E. Berghof-Hasselbächer, P. Gawenda, M. Schorr, M. Schütze, J.J. Hoffman, Atlas of Microstructures, Materials Technology Institute 
28. D. Oquab, N. Xu, D. Monceau, D.J. Young, Subsurface microstructural changes in a cast heat resisting alloy caused by high temperature corrosion. Corros. Sci. 52, 255-262 (2010)

29. R. Voicu, E. Andrieu, D. Poquillon, J. Furtado, J. Lacaze, Microstructure evolution of HP40-Nb alloys during aging under air at $1000^{\circ} \mathrm{C}$. Mater. Charact. 60, 1020-1027 (2009)

30. K.J. Stevens, A. Parbhu, J. Soltis, D. Stewart, Magnetic force microscopy of a carburized ethylene pyrolysis tube. J. Phys. D 36, 164-168 (2003)

31. M.W. Mucek, Laboratory detection of degree of carburization in ethylene pyrolysis furnace tubing. Mater. Perform. 22, 25-28 (1983)
32. I.C. da Silva, R.S. da Silva, J.M.A. Rebello, A.C. Bruno, T.F. Silveira, Characterization of carburization of HP steels by non destructive magnetic testing. NDT E Int. 39, 569-577 (2006)

33. L.R. Jackson, H.W. Russell, Temperature-sensitive magnetic alloys and their uses. Instruments 11, 280-282 (1938)

34. T. Hara, T. Okiyama, T. Takemoto, Improvement of soft magnetic properties by $\mathrm{Cr}$ addition for $\mathrm{Fe}-(34-46)$ mass\% $\mathrm{Ni}$ alloys. J. Jpn Inst. Metals 60, 1136-1142 (1996). (in Japanese)

35. P. Chevenard, La precision en metallurgie et la metallurgie de precision. Mem. Soc. Ing. Civ. (France) 104, 1-44 (1951). (in French) 